\title{
Legal Approaches in Lethal Diseases Genes; The Case of Recurrent Achondrogenesis Type Garcia-Ramirez
}

\author{
Aguilar-Aldrete $\mathrm{ME}^{1}$, Ramirez-Garcia SA ${ }^{2 *}$, Juárez-Pérez $\mathrm{MH}^{3}$ and Flores-Alvarado $\mathrm{LJ}^{4}$ \\ ${ }^{1}$ Department of Public Health, CUCS, University of Guadalajara, México \\ ${ }_{2}^{2}$ Institute of Nutrition, University of the Sierra Sur, Miahuatlán De Porfirio Díaz, Oaxaca, México \\ ${ }^{3}$ Institute of Public Health Research, University of the Sierra Sur, Miahuatlán De Porfirio Díaz, Oaxaca, México \\ ${ }^{4}$ Department of Molecular and Genomic Biology, CUCS, University of Guadalajara, México
}

*Corresponding author : Sergio Alberto Ramirez Garcia, Institute of Nutrition, University of the Sierra Sur, Miahuatlán De Porfirio Díaz, Oaxaca, México

Received Date: November 15, 2019

Published Date: November 19, 2019

\begin{abstract}
The legal medical approach to family members with relatives who have lethal diseases is complex, because many of them are incompatible with life such as tanatoforic dysplasia and achondrogenesis. It is complex considering several issues; As they are due to mutations in lethal genes, the products are incompatible with life, or die in the first days after birth. And for their complete study, it is necessary to take blood samples or biopsies of several tissues from the relatives of the patients, to extract DNA, RNA and look for de novo mutations, germ mutations and other hand.
\end{abstract}

Keywords: Achondrogenesis; Legal approach; Bone dysplasia; Lethal genes; Recurrent disease

\section{Opinion}

Dear editor, from the point of view of law and medicine, the advice of family members with patients who have lethal diseases are complex, because many of them are incompatible with life such as tanatoforic dysplasia and achondrogenesis. It is complex considering several points; As they are due to mutations in lethal genes, the products are incompatible with life, or die in the first days after birth. And for their study it is necessary to take blood samples or biopsies of several tissues from the relatives of the patients, to extract DNA, RNA and look for de novo mutations, germ mutations, and/or mechanisms. In this sense, as it implies risk, it is very difficult for family members to agree to participate in the study, especially when they are asymptomatic or when they have not apparent benefit. For this reason, specialists in the area of orthopedics, genetics and pediatrics, who are the ones who attend to these patients, must raise awareness among family members so that they can participate, weighing the risk of benefit [1-5].

It is possible that molecular studies serve to prevent other cases in subsequent pregnancies. If it's a limitation, because in many hospitals, studies are not approved in asymptomatic relatives or even in the corpses of stillbirths, or severely affected unborn, for issues related to the integrity and risk benefit of the patient-family members. Recently we publish a new variant of achondrogenesis, which could be explained by mutations in the type 10 collagen gene, however, the study could not be completed because the study was not authorized in relatives due to risk or benefit issues [1-5].

In many cases of lethal gene diseases, there are abortions and/or recurring still born, because are incompatible with life. In these cases, is very important to manage the authorization of family members and hospital bioethics committees, so that the forensic pathologist, criminalist or geneticist made the molecular complementary study in search of the mutation [1-5].

The immunohistochemical study is complementary to jointly estimate the cause of death and prevent future family cases and populations. In this sense we studied a case with a new variant of achondrogenesis $1 \mathrm{~A} 1$, whose family history was recurrent abortions, of which there was no tissue or DNA sample. A histopathological study was made of the case index that demonstrated the absence of alterations in the collagen and the presence of a struc- 
tural disorder such as vacuolated chondrocytes, which allowed the diagnosis of achondrogenesis in the patient. It was proposed as a new variant because it did not present the inheritance pattern of the four current types reported, however it is to be known that the product died minutes later, and the relatives was no longer authorized more studies to the index case.

With these considerations, it is necessary that the treating physicians, the forensic pathologist and the hospitals establish protocols for the diagnosis and prevention of these conditions, with the respective bioethical and legal considerations, so that it is not a limitation in establishing the exact cause or etiology of lethal diseases in order to establish a better genetic counseling of their family. These would be the most important considerations at the level of molecular autopsy.

\section{Acknowledgement}

None

\section{Conflicts of Interest}

None.

\section{References}

1. Ramirez GSA, Garcia CD, Bitar AWE, Baltazar RLM, Montano CB, et al. (2019) Recurrent achondrogenesis type $1 \mathrm{~A} 1$ is due to allelic variant of the COL10A1 geneCOL10A1? Cir Cir 87(5): 602-604.

2. Ramirez GSA, Garcia CD, Cervantes AI, Bitar AWE, Davalos R IP, et al. (2018) New subtype of familial achondrogenesis type IA (HoustonHarris). Cir Cir 86(1): 81-89.

3. Warman ML, Abbott M, Apte S, Hefferon T, McIntosh I, et al (1993) A type $\mathrm{X}$ collagen mutation causes Schmid metaphyseal chondrodysplasia. Nature Genet 5: 79-82.

4. Aiger T, Rac T, Niederhagen M, Zaucke F, Schmitz M, et al (2007) Achondrogenesis type 1A (Houston-Harris): a still-unresolved molecular phenotype. Pediatr Dev Pathol 10(4): 328-334.

5. Bateman JF, Freddi S, Nattrass G, Savarirayan R (2003) Tissue-specific RNA surveillance?Nonsense-mediated mRNA decay causes collagen X haploinsufficiency in Schmid metaphyseal chondrodysplasia cartilage. Hum Molec Genet 12(3): 217-25. 